
\title{
R Reserach S Suare \\ Effect of Cutting Flute Offset and Surface Treatment on Self-tapping Bone Screw
}

\section{Changsheng Chen}

Hohai University

Aimin Ji ( jam@ustc.edu )

College of Mechanical and Electrical Engineering, Hohai University, Changzhou 213022, China

Zhonghang Zhao

Hohai university

Lingjie Fu

Ninth people's hospital, Shanghai Jiaotong University school of medicine

\section{Research}

Keywords: Self-tapping bone screw, cutting flute offset, surface treatment, insertion torque, pullout strength

Posted Date: January 4th, 2021

DOI: https://doi.org/10.21203/rs.3.rs-136226/v1

License: (c) (i) This work is licensed under a Creative Commons Attribution 4.0 International License.

Read Full License 


\section{Abstract}

Background: Self-tapping bone screws hard to insert will brings many surgical risks such as damage the bone, screw failure. This study investigated the effect of different cutting flute offset and different surface treatment on the insertion torque and pullout strength for self-tapping bone screws.

Methods: Titanium alloy screws with five types cutting flute offset and two types surface treatment, were tested for maximum insertion torque and pullout strength in a simulation cortical bone material. One group of each type surface treatment screws were tested for torsional properties. All tests were principally performed according to bone screws test standard.

Results: For two types surface treatment, the insertion torque of design with $0.4 \mathrm{~mm}$ offset was less than others cutting flute offset ( $\mathrm{p} \otimes 0.05$ ), and the pullout strength of design with $0.2 \mathrm{~mm}$ offset was bigger than others group ( $\mathrm{p} \varangle 0.05$ ). Compared two surface treatment, the insertion torque of dark anodized screws was less than bead blasted, and the former pullout strength was bigger than the latter screws with the offset from $0 \mathrm{~mm}$ to $0.4 \mathrm{~mm}(\mathrm{p} \otimes 0.05)$.

Conclusions: The study results show that different cutting flute offset design and surface treatment effect on the insertion torque, and the bigger cutting flute offset has the lower inserting resistance, and the comprehensive performance of dark anodized screws were better than bead blasted.

\section{Background}

Self-tapping functional design of bone screw has been widely used in surgical operation. Like selftapping cortical screws, cancellous screws, pedicle screws, cannulated screws and so on are commonly used in trauma, spine, joint replacement and bone graft surgery, meanwhile, non-self-tapping screws are also currently available ${ }^{[1,2]}$. It has been suggested that insertion torque and pullout strength were two significant properties for bone screws ${ }^{[3,4]}$, and were principally obtain in experimental method according to ASTM F543 ${ }^{[5]}$. Early research reported that similar pullout strength between self-tapping and non-selftapping screws in vivo or vitro models ${ }^{[6]}$. However self-tapping screws can decrease surgical steps, reduce surgical instruments and time of operation as compared with no-self-tapping screws ${ }^{[7,8]}$. There also has reported that insertion torque of self-tapping screws was lower and pullout strength was higher than conventional pre-tapped screws ${ }^{[9]}$.

As we know the lower insertion torque, the higher safety against rotation resistance during screw insertion. Unwanted screws or screwdrivers breakage maybe direct result of excessive insertion torque due to the thread cutting resistance more than screw strength or screwdrivers strength. One case is the self-tapping screw fractured at thread during insertion (Fig. 1), and another case is two screwdrivers fractured during insert screw (Fig. 2). Also we believed the higher the pullout strength, the higher is the capability of screws to resist lag forces ${ }^{[10,11]}$. So we expected relative lower insertion torque, and higher pullout strength. Although numbers of research has focus on the design of thread pitches, cutting flute 
lengths and cutting flute numbers on influence of self-tapping screws insertion torque and pullout strength ${ }^{[12,13,14]}$. William et al. ${ }^{[15]}$ the bigger thread pitches of screws has the higher insertion torque, but different screw pitches designs is unrelated to their pullout strength in in a model of osteoporotic cancellous bone. And Scott et al. ${ }^{[3]}$ reported screws with more than two flutes were easier to insert and did not cause cortical damage during insertion and the screw with four full-length flutes showed a trend toward being the easiest to insert and having the greatest holding strength, but more and longer cutting flutes may lead to soft tissue irritation ${ }^{[16]}$. Therefore, less cutting flutes number and shorter cutting flutes length may benefit the patient. We need to consider other methods to improvement the self-tapping screw performance of insertion torque and pullout strength.

We find little research has focus on the design of cutting flute offset and surface treatment of selftapping screws. Previous studies showed that bone drill bit cutting flute offset was a critical factor and was inversely related to the bone cutting efficiency. However to date there was no data for how cutting flute offset could influence the performance of self-tapping bone screw ${ }^{[14,17]}$. And earlier Frank et al. ${ }^{[7]}$ reported the geometry of the cutting flutes in bone screws has a considerable effect on the insertion torque and pullout strength, this depends on machining and surface treatment procedure (mechanical and/or electro-polishing). This study was designed to evaluate the effect of cutting flute offset and surface treatment on self-tapping bone screw in a surrogate cortical bone model, and compared with screws maximum torque and torsional yield strength, find a more safety design solution.

\section{Results}

\section{Roughness}

The mean roughness of bead blasted surface treatment was $0.771 \mathrm{um}$, and the mean roughness of dark anodized was 0.624 um (Table 1 ), the latter surface treatment was significantly (pष0.0001) lower than the former, lower surface roughness means lower surface friction coefficient.

\section{Torsional property}

The mean maximum torque of bead blasted screws was $2.85 \mathrm{~N} \mathrm{~m}$, and yield torque was $2.12 \mathrm{~N} \mathrm{~m}$, there were not show significant difference for dark anodized screws in maximum torque $2.88 \mathrm{~N} \mathrm{~m}(p=0.14)$ and yield torque $2.15 \mathrm{~N} \mathrm{~m} \mathrm{(} \mathrm{p}=0.12)$ (Table 1$)$. We found that the two surface treatments not significantly influence the screw mechanical properties. 
Table 1

Roughness and torsional test results of two surface treatment

\begin{tabular}{|llll|}
\hline Surface treatment & Ra Roughness (SD) & Maximum Torque (SD) & Yield Torque (SD) \\
\hline Bead blasted & $0.771(0.061)$ & $2.85(0.07)$ & $2.12(0.05)$ \\
\hline Dark anodized & $0.624(0.046)$ & $2.88(0.05)$ & $2.15(0.04)$ \\
\hline $\begin{array}{l}\text { SD, standard deviation; Ra Roughness (um); Maximum Torque (Nm); Yield Torque (Nm); values are } \\
\text { expressed as mean (SD). }\end{array}$
\end{tabular}

\section{Insertion testing}

For bead blasted screws, the mean maximum insertion torque of design e was significantly (p囚0.05) lower than those for designs $\mathrm{a}, \mathrm{b}$ and $\mathrm{c}$ (Table 2), and for dark anodized screws, the mean maximum insertion

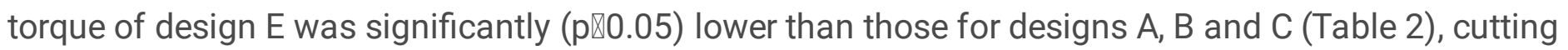
flute offset was significantly influence the mean insertion torque, and we found that the linear decreasing trend of insertion torque as the cutting flute offset increasing (Fig. 3, Fig. 4) for same to two surface. Compared two surface treatments, the insertion torque of dark anodized screws was significantly (pख0.05) lower than bead blasted screw for cutting flute offset of $0 \mathrm{~mm}, 0.1 \mathrm{~mm}, 0.2 \mathrm{~mm}$.

Table 2

Maximum insertion torque and pullout strength for different cutting flute offset

\begin{tabular}{|lll|}
\hline Offset/Screw design & MIT (SD) & POS (SD) \\
\hline $0 \mathrm{~mm} / \mathrm{a}$ & $2.73(0.07)$ & $2744(39)$ \\
\hline $0.1 \mathrm{~mm} / \mathrm{b}$ & $2.42(0.25)$ & $2749(33)$ \\
\hline $0.2 \mathrm{~mm} / \mathrm{c}$ & $1.85(0.21)$ & $2770(32)$ \\
\hline $0.3 \mathrm{~mm} / \mathrm{d}$ & $1.01(0.12)$ & $2760(31)$ \\
\hline $0.4 \mathrm{~mm} / \mathrm{e}$ & $1.03(0.22)$ & $2764(56)$ \\
\hline $0 \mathrm{~mm} / \mathrm{A}$ & $2.49(0.16)$ & $2802(16)$ \\
\hline $0.1 \mathrm{~mm} / \mathrm{B}$ & $1.77(0.41)$ & $2833(18)$ \\
\hline $0.2 \mathrm{~mm} / \mathrm{C}$ & $1.48(0.32)$ & $2867(47)$ \\
\hline $0.3 \mathrm{~mm} / \mathrm{D}$ & $0.91(0.07)$ & $2812(18)$ \\
\hline $0.4 \mathrm{~mm} / \mathrm{E}$ & $0.83(0.06)$ & $2799(21)$ \\
\hline $\begin{array}{l}\text { SD, standard deviation; MIT, Maximum insertion torque (Nm); POS, pullout strength (N); values are } \\
\text { expressed as mean (SD). }\end{array}$ & \\
\hline
\end{tabular}

\section{Pullout strength testing}


For bead blasted screws, the mean pullout strength shows no significant difference of five designs(P凶0.05) (Table 2, Fig. 5), and for dark anodized screws, the mean pullout strength of design $\mathrm{C}$ was significantly ( $\mathrm{p} \otimes 0.05$ ) higher than those for designs A, D and E (Table 2, Fig. 6). Compared two surface treatments, the mean pullout strength of dark anodized screws was significantly ( $\mathrm{p} \otimes 0.05)$ higher than bead blasted screw for cutting flute offset of $0 \mathrm{~mm}, 0.1 \mathrm{~mm}, 0.2 \mathrm{~mm}$ and $0.3 \mathrm{~mm}$.

\section{Discussion}

If screws hard to insert will add many surgical risks include damage the bone, heat generation, screw failure or screwdriver fracture, that would be many unexpected results occur in operation room may lead to more operation steps and time, patients slower recovery, even failure of operation ${ }^{[10,16,20]}$. If screw has lower pullout strength, that maybe couldn't maintain construct stability of internal fixation in healing process. For example, nonlocked plate-screw construct, the screw may retreat from the bone and matched plate, and locked plate-screw construct, the plate and screw construct may retreat from the bone because of lack of holding power, that would be lead to soft tissue irritation or interference with muscle and result in patient discomfort or pain, even may lead to fixation failure needed a second operation. Current study indicated that surgeons prefer a self-tapping screw that starts easily, and expect lower insertion torque that operates comfortable, but also choose higher holding power with stable fixation. As we know many design factors influence the final insertion torque and pullout strength of the self-tapping screws, such as design of cutting flute, thread, surface treatment, and matched drill bit.

The goal of this study was to investigate the effect of cutting flute offset and surface treatment on the insertion and pullout performance of self-tapping screws, and leaving all other parameters equal. Surrogate bone material was used as a substitute for human cortical bone because of biomechanical similarity and uniformity test condition. The results of this study indicate that the insertion torque become lower trend with the cutting flute offset added (Fig. 3 and Fig. 4), but the pullout strength did not show significant differences (Fig. 5 and Fig. 6), and compared two surface treatment, the insertion torque and pullout strength of dark anodized screws was significantly better than bead blasted screw for cutting flute offset of $0 \mathrm{~mm}, 0.1 \mathrm{~mm}, 0.2 \mathrm{~mm}$. From the torsional test, we got the screw relative mechanical property of maximum torque and yield torque, the safety insertion torque was ideally lower than screw yield torque, that's ensure the screw not failure and decrease resistance of the driver bit during operation, offset $0.2 \mathrm{~mm}, 0.3 \mathrm{~mm}$ and $0.4 \mathrm{~mm}$ were better chose. From the roughness results found that dark anodized surface has low friction make screw ease to insert and also higher pull strength, offset $0.2 \mathrm{~mm}$ was the best design with pullout strength.

There are many other factors that might influence insertion torque and pullout strength, here only considered five cutting flute offset and two surface treatment, and used surrogate bone material might influence the test results precision. Clinic use also meeting many others surgical risks we not research in this study, like screw stripping was an important aspect of clinic failure risk ${ }^{[21]}$. This study just clearly indicates that cutting flute offset design and surface treatment choice could gave us the ideally application requirement. 


\section{Conclusion}

We designed experiments on insertion torque and pullout strength for self-tapping bone screws with different cutting flute offset and two surface treatments. It is found that the cutting flute offset has a significant influence on the insertion torque of the screw, which provides a method to reduce the failure of the screw and the difficulty of insertion during the operation. The insertion torque decreased clearly with the increase of the cutting flute offset, but the effect on the pull-out strength was gentle. In addition, within a certain range of cutting flute offset, the improvement of the screw with dark anodized surface treatment is higher than bead blasted from the perspective of comprehensive properties.

\section{Methods}

\section{Experimental overview}

Five types of self-tapping screws with varying cutting flute offset designs, and two different surface treatments, total ten test groups were inserted in uniform simulated human cortical bone materials for the purpose of evaluating self-tapping screw insertion torque and pullout strength. In addition, two groups of surface treatment screws were tested for surface roughness torsional properties. Six screws were tested for each group situation. All data were statistically analyzed using a one way analysis of variance with a level of significance of 0.05 to determine differences among means.

\section{Screws}

Custom manufactured Ti-6Al-4V alloy screws were used for all tests (Fig. 7). All screws had an identical $3.5 \mathrm{~mm}$ major diameter, a $2.4 \mathrm{~mm}$ minor diameter, a $1.25 \mathrm{~mm}$ thread pitch, and so on, these design parameters reference to ASTM F543 ANNEXES $5^{[5]}$, and all screws design with same three cutting flutes and $4.5 \mathrm{~mm}$ same flute lengths, same total $40 \mathrm{~mm}$ lengths, but with varying different cutting flute offset design (Fig. 8). This study chose the final surface treatments of screw were commonly used in orthopaedic surgery for use bead blasted process and dark anodized process, these two surface treatments were applied in titanium-made implants for decades. 10 groups test samples list as Table 3. 
Table 3

Variations in cutting flute offset and surface treatment

\begin{tabular}{|lll|}
\hline Screw design & Offset value(q) & Surface treatment \\
\hline a & $0 \mathrm{~mm}$ & Bead blasted \\
b & $0.1 \mathrm{~mm}$ & Bead blasted \\
\hline c & $0.2 \mathrm{~mm}$ & Bead blasted \\
\hline d & $0.3 \mathrm{~mm}$ & Bead blasted \\
\hline e & $0.4 \mathrm{~mm}$ & Bead blasted \\
\hline A & $0 \mathrm{~mm}$ & Dark Anodized \\
\hline B & $0.1 \mathrm{~mm}$ & Dark Anodized \\
\hline C & $0.2 \mathrm{~mm}$ & Dark Anodized \\
\hline D & $0.3 \mathrm{~mm}$ & Dark Anodized \\
\hline E & $0.4 \mathrm{~mm}$ & Dark Anodized \\
\hline
\end{tabular}

\section{Simulation cortical bone material}

For compared different screw designs at the relative uniformity test situation, many researchers used simulated material instead of human bone ${ }^{[15,18,19]}$. This study used synthetic biomechanical bone material was manufactured from solid rigid block of BM5166 (HUNTSMAN, Switzerland) instead of human bone. The uniformity and consistent properties of solid block make it an ideal material for comparative testing of bone screw, with density $1.7 \mathrm{~g} / \mathrm{cm}^{3}$, compressive stress $95 \mathrm{MPa}$, compressive modulus $7000 \mathrm{MPa}$, for flexural strength $60 \mathrm{MPa}$. Each test foam block manufactured $10 \mathrm{~mm}$ thickness, and pre-drilled $2.5 \mathrm{~mm}$ diameter hole used a $2.5 \mathrm{~mm}$ surgical matched drill bit, all with machining finished ensure uniform test situation.

\section{Roughness testing}

First tested two final surface treatment of bead blasted and bark anodized for Ra roughness with surface roughometer (SJ-410, Mitutoyo), here used substitute column specimen of $3.5 \mathrm{~mm}$ diameter with same material and process, because screw with complex surface is hard to test roughness directly.

\section{Torsional testing}

Place the screw in the holding device so that five threads, below the head of the screw are exposed outside the holding device (Fig. 9). The screw head was driven by the test machine (Z5.0TN) and a $20 \mathrm{~N} \mathrm{~m}$ torque sensor (Zwick, accuracy of $\pm 0.5 \%$ of reading from $5 \%$ to full scale of torque cell), by applying a torsion speed of $3 \mathrm{r} / \mathrm{min}$ until the screw breakage according to ASTM F543 ANNEXES 1 test 
method. Record torsional yield strength and maximum torque. This test result was irrelevant to cutting flute design, so here each surface treatment tested one group with $0 \mathrm{~mm}$ offset.

\section{Insertion testing}

Placed the specimen in the test fixture (Fig. 10), the specimens were driven into the test block, using the appropriate screwdriver bit on the test machine (Z5.0TN) and a $20 \mathrm{~N} \mathrm{~m}$ torque sensor (Zwick, accuracy of $\pm 0.5 \%$ of reading from $5 \%$ to full scale of torque cell), by applying a torsional force at a rate of $5 \mathrm{r} / \mathrm{min}$ with continuous augmentation until screw tip cutting flutes full protruded underside of test block. According to ASTM F543 ANNEXES 2 the maximum insertion torque was measured during the initial four revolutions. A $10 \mathrm{~N}$ axial preload was used to maintain the screwdriver bit in the screw head during insertion test with a $500 \mathrm{~N}$ load sensor (Zwick, accuracy of $\pm 0.5 \%$ of reading from $5 \%$ to full scale of load cell).

\section{Pullout strength testing}

After each screw with insertion test go on to pullout test, place the test sample with block in another experimental testing apparatus mounted in test machine (Z5.0TN) (Fig. 11). The test block was supported by a stainless steel frame with a hole for screw head traverse, the screw head placed in the slot of load fixture and seated in the spherical recess according to ASTM F543 ANNEXES 3. The load fixture applied to screw at constant rate of $5 \mathrm{~mm} / \mathrm{min}$ with a $5000 \mathrm{~N}$ load sensor (Zwick, accuracy of $\pm 0.5 \%$ of reading from $5 \%$ to full scale of load cell) until the screw failed or released from the test block, record the maximum force as pullout strength.

\section{Abbreviations}

ASTM

American Society for Testing Materials; SD:Standard deviation; MIT, Maximum insertion torque; POS, Pullout strength.

\section{Declarations}

\section{Acknowledgements}

Not applicable.

\section{Authors' contributions}

CC performed experiments and wrote the manuscript, LF conceived the experiments, ZZ processed the data, AJ revised the manuscript.

\section{Funding}


This work was supported by the Fundamental Research Funds for the Central Universities (KYCX20_0532, B200203153).

\section{Availability of data and materials}

Data sharing not applicable to this article as no datasets were generated or analyzed during the current study.

\section{Ethics approval and consent to participate}

Not applicable.

\section{Consent for publication}

Not applicable.

\section{Competing interests}

The authors declare that they have no competing interests.

\section{References}

[1] Schatzker J, Sanderson R, Murnaghan JP. The holding power of orthopedic screws in vivo. Clin Orthop. 1975; 108: 115-126.

[2] Trader JE, Johnson RP, Kalbfleisch JH. Bone-mineral content, surface hardness, and mechanical fixation in the human radius. A correlative study. J Bone Joint Surg [Am] 1979; 61: 1217-1220.

[3] Scott Yerby, C. Corey Scott, Nathan J. Evans, et al. Effect of Cutting Flute Design on Cortical Bone Screw Insertion Torque and Pullout Strength. Journal of Orthopaedic Trauma. 2001; 15(3):216-221.

[4] Lawson KJ, Brems J. Effect of insertion torque on bone screw pullout strength. Orthopedics. 2001; 24:451-454.

[5] ASTM F543-13, Standard Specification and Test Methods for Metallic Medical Bone Screws. In: Annual Book of ASTM Standards. Section 13. Medical Devices and Services. American Society for Testing and Materials, 2016; pp: 127- 148.

[6] Thompson JD, Benjamin JB, Szivek JA. Pullout strengths of cannulated and noncannulated cancellous bone screws. Clin Orthop. 1997; 341: 241-249.

[7] Baumgart FW, Cordey J, Morikawa K, et al. AO/ASIF self-tapping screws (STS). Injury. 1993; 24: S1-7.

[8] Bickley MB, Hanel DP. Self-tapping versus standard tapped titanium screw fixation in the upper extremity. J Hand Surg [Am] 1998; 23: 308-311. 
[9] Ansell RH, Scales JT. A study of some factors which affect the strength of screws and their insertion and holding power in bone. J Biomech. 1968;1:279-302.

[10] Boyle JMD, Frost DE, Foley WL, et al. Torque and pullout analysis of six currently available selftapping and 'emergency' screws. J Oral Maxillofac Surg. 1993; 51: 45-50.

[11] Koranyi E, Bowman CE, Knecht CD, et al. Holding power of orthopedic screws in bone. Clin Orthop. 1970; 72: 283-286.

[12] Battula S, Schoenfeld AJ, Sahai V, et al. The effect of pilot hole size on the insertion torque and pullout strength of self-tapping cortical bone screws in osteoporotic bone. J Trauma. 2008; 64:990-995.

[13] Chapman JR, Harrington RM, Lee KM, et al. Factors affecting the pullout strength of cancellous bone screws. J Biomech Eng. 1996; 118:391-398.

[14] Evans $M$, Spencer M, Wang Q, et al. Design and testing of external fixator bone screws. J Biomed Eng. 1990; 12: 457-462.

[15] William M.R., Paul T, Timothy P, et al. A comparison of screw insertion torque and pullout strength. Journal of Orthopaedic Trauma. 2010, 24(3):374-378.

[16] Bechtol CO. Internal fixation with plates and screws. In: Metals and Engineering in Bone and Joint Surgery, ed by Bechtol CO, Ferguson AB, Lang PG. Baltimore, Williams and Wilkins, 1959.

[17] You ZH, Bell WH, Schneiderman ED, et al. Biomechanical properties of small bone screws. J Oral Maxillofac Surg. 1994; 52:1293- 1302.

[18] Thomas AD, David BH, Daniel JD, et al. Optimizing bone screw pullout force. Journal of Orthopaedic Trauma. 1990; 4(2):169-194.

[19] Murphy TP, Hill CM, Kapatkin AS, et al. Pullout properties of 3.5-mm AO/ASIF self-tapping and cortex screws in a uniform synthetic material and in canine bone. Vet Surg. 2001; 30: 253-260.

[20] Phillips JH, Rahn BA. Comparison of compression and torque measurements of self-tapping and pretapped screws. Plast Reconstr Surg. 1989; 83: 447-458.

[21] Radek C, Karel F, Frantisek S, et al. Analysis of locking self-taping bone screws for angularly stable plates. J. Med. Biol. Eng. 2017; 37: 612-625.

\section{Figures}




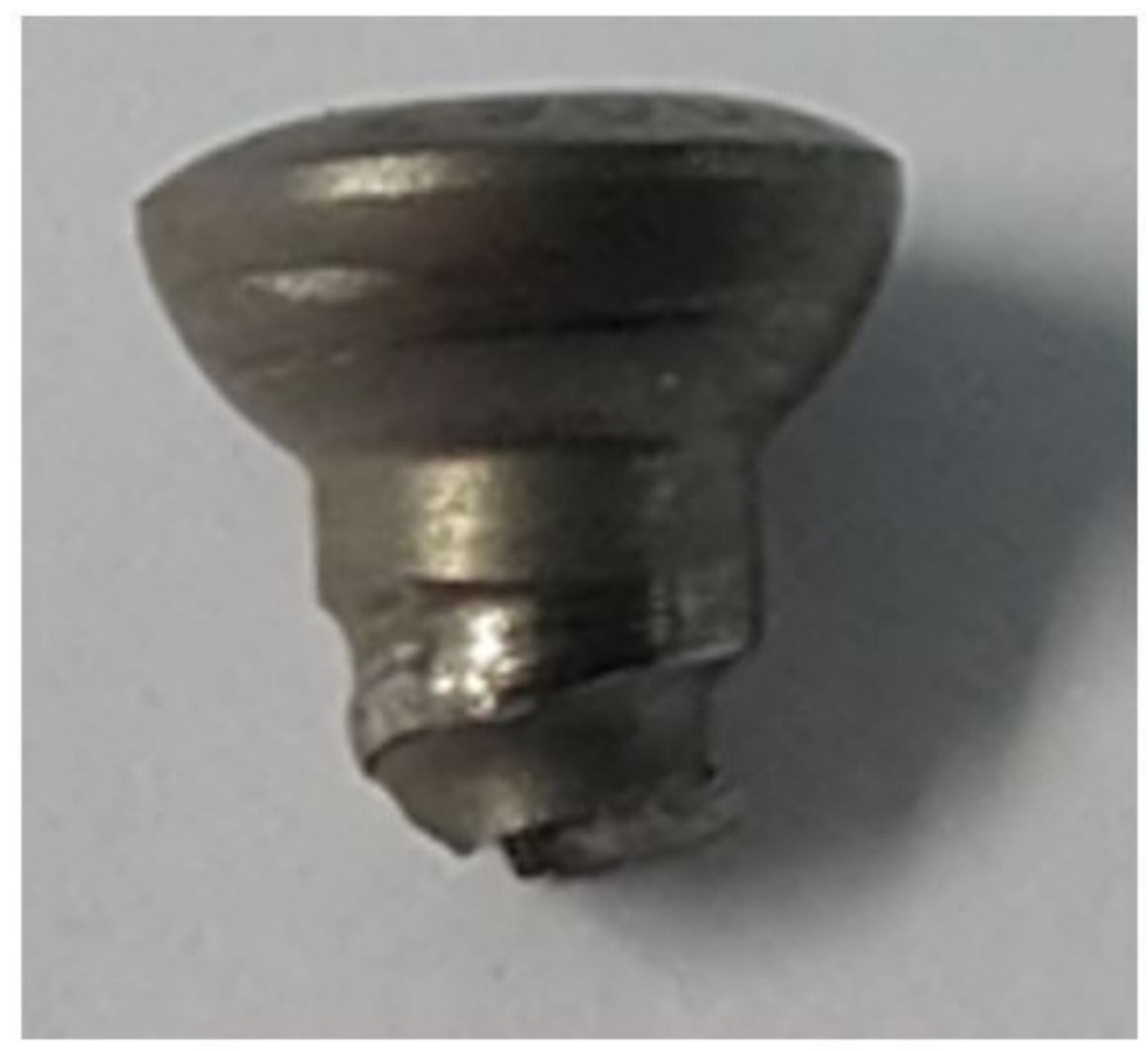

Figure 1

one insertion failure case of self-tapping bone screw 


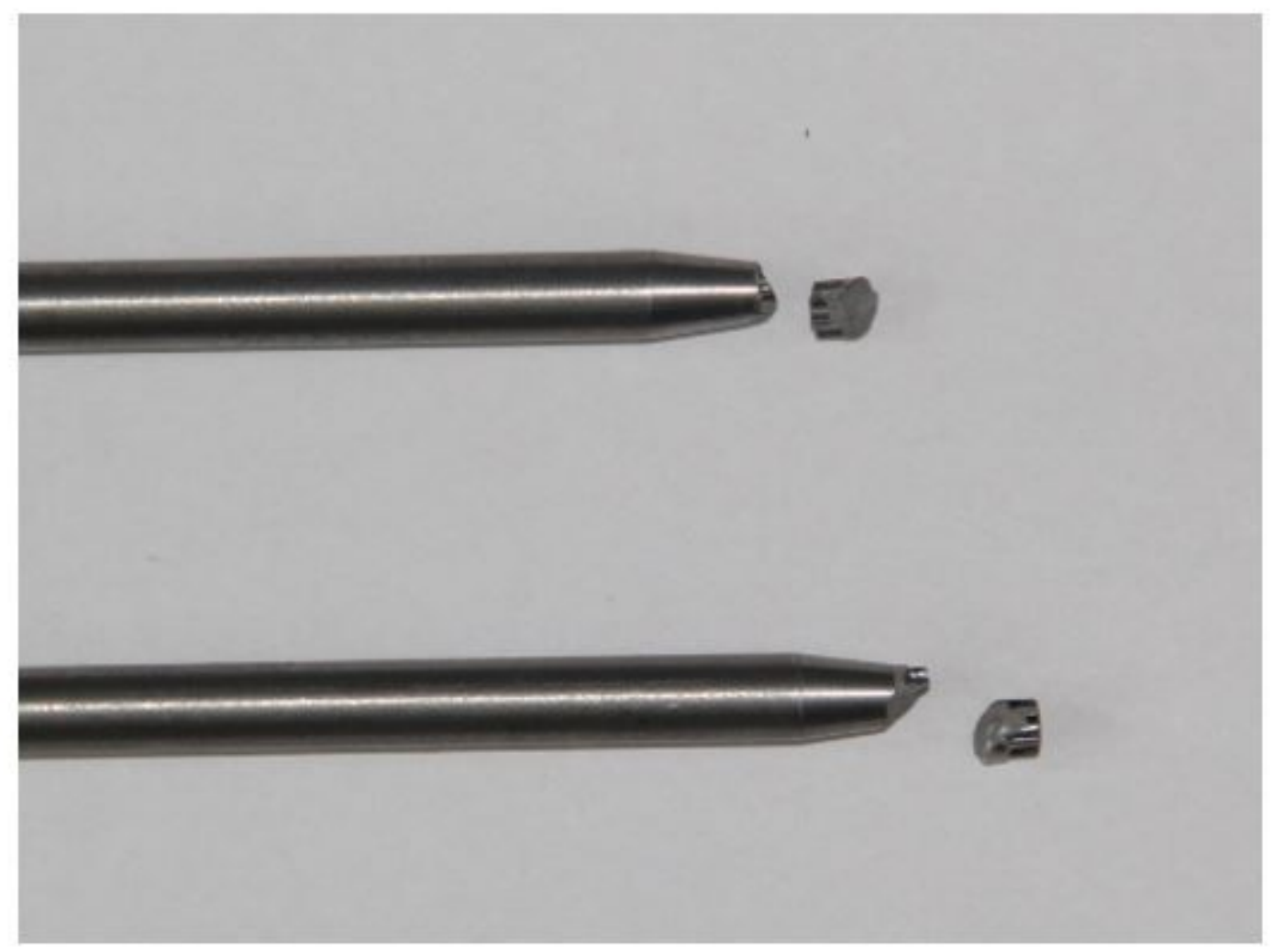

Figure 2

Two insertion failure cases of driver 


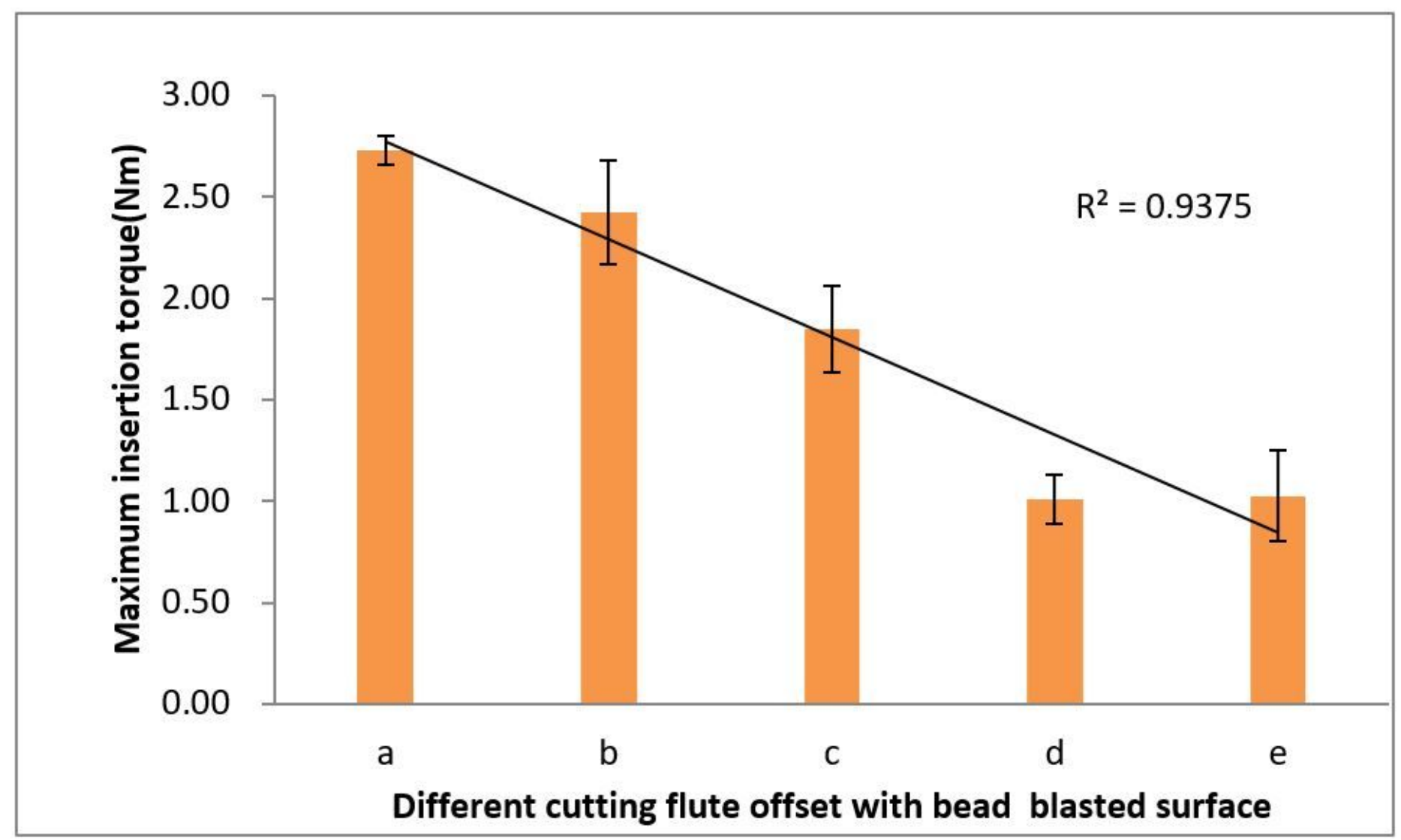

Figure 3

A bar chart of maximum insertion torque for each screw design of bead blasted regression analysis. 


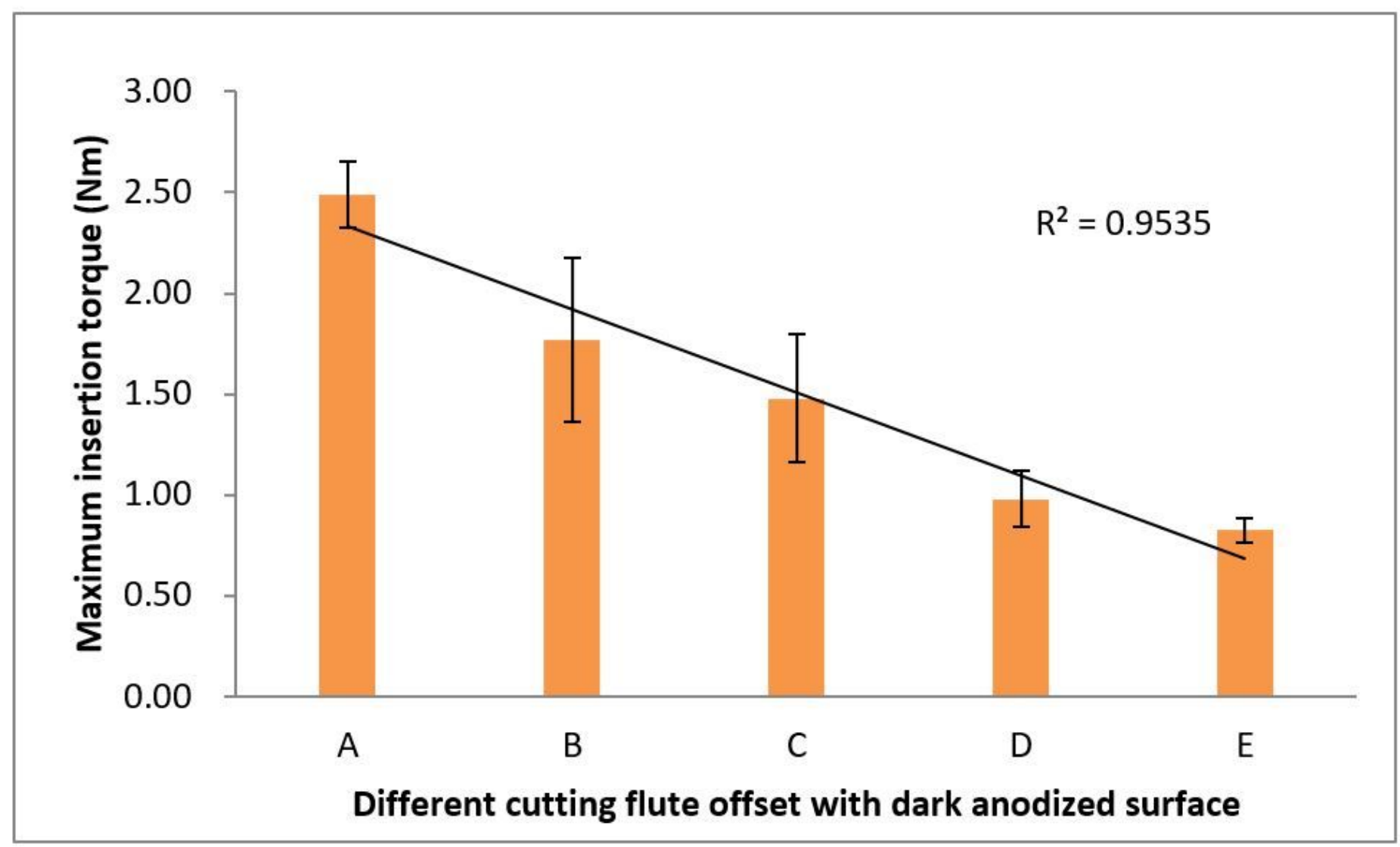

Figure 4

A bar chart of maximum insertion torque for each screw design of dark anodized with regression analysis. 


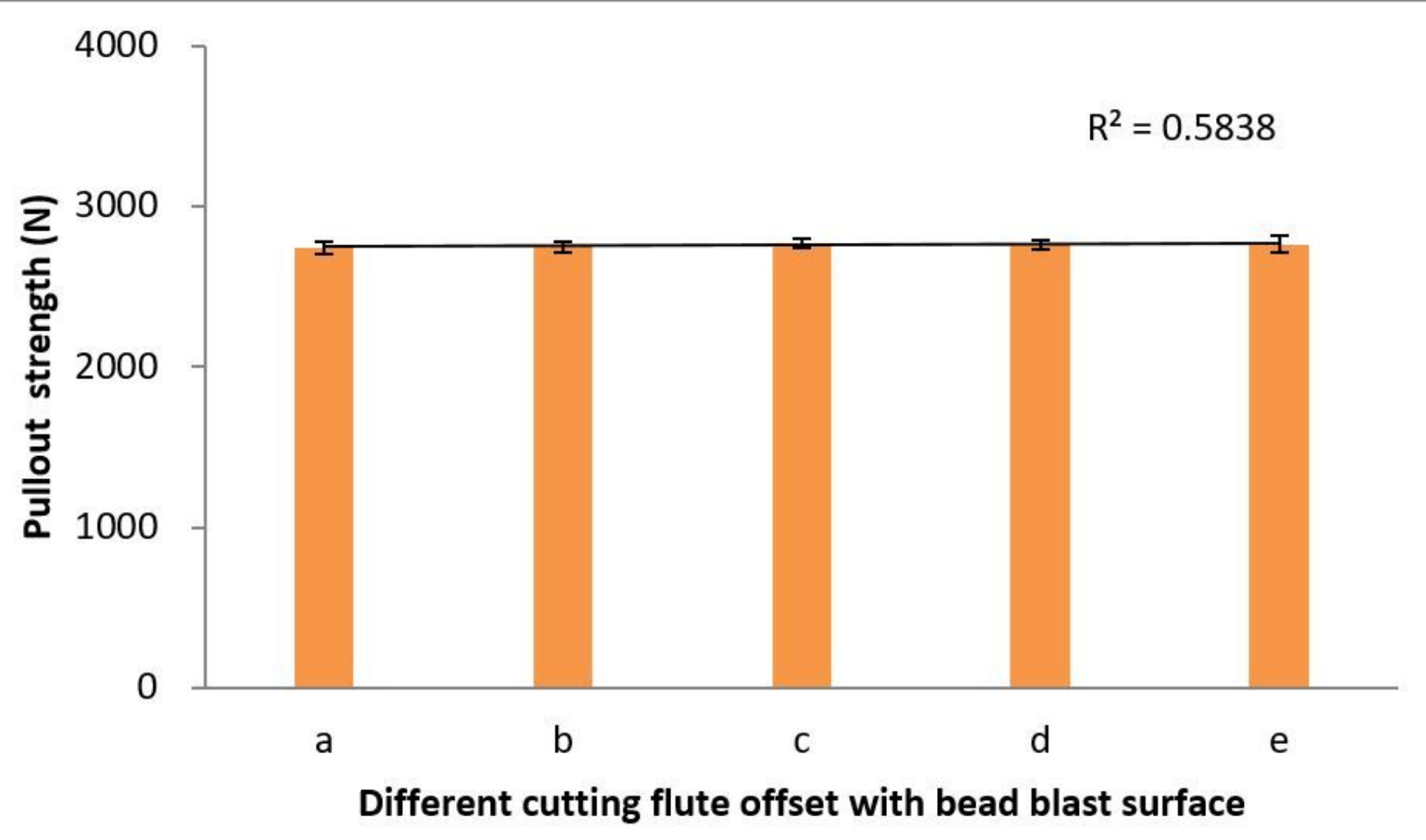

Figure 5

A bar chart of pullout strength for each screw design of bead blasted with regression analysis.

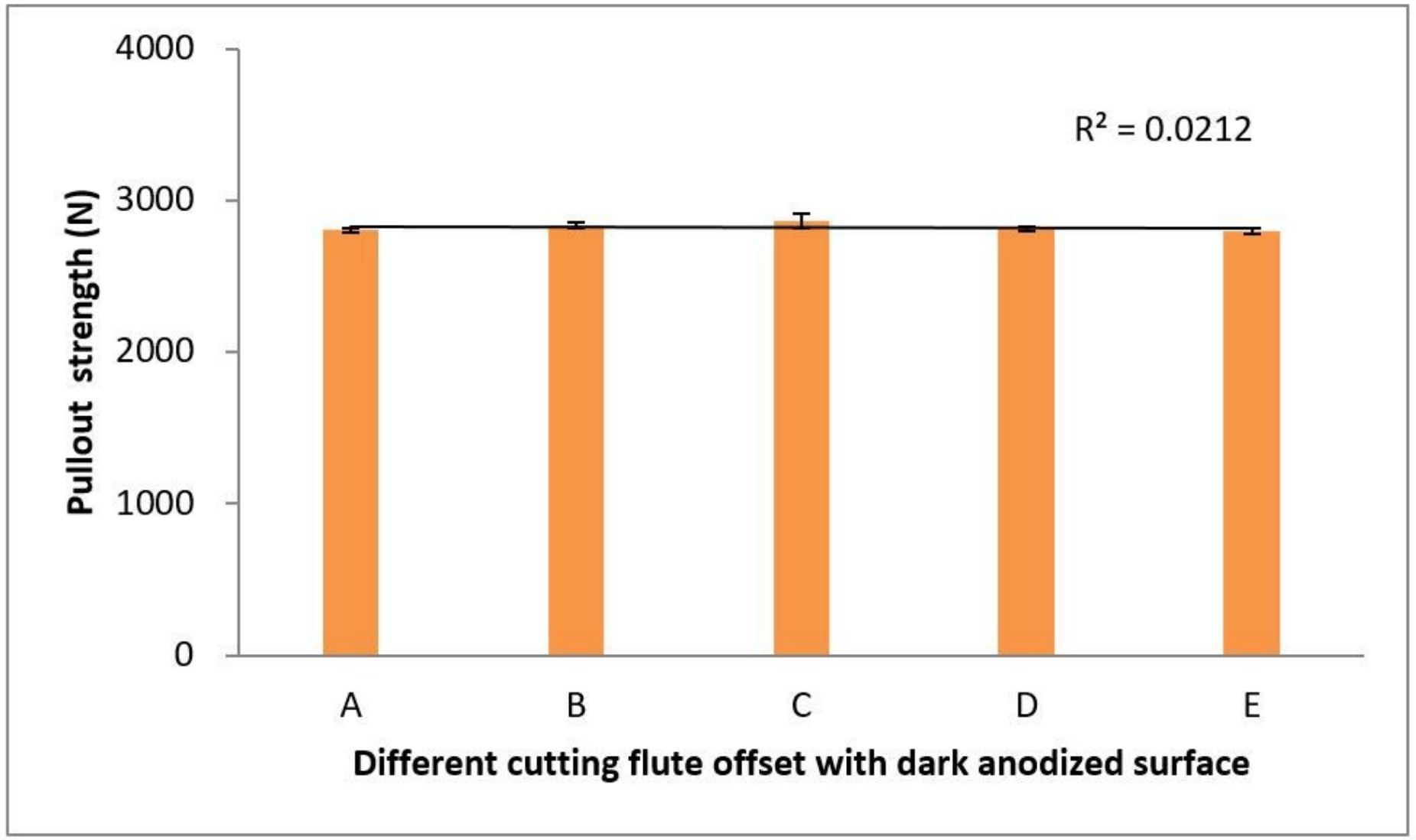


Figure 6

A bar chart of pullout strength for each screw design of dark anodized with regression analysis.

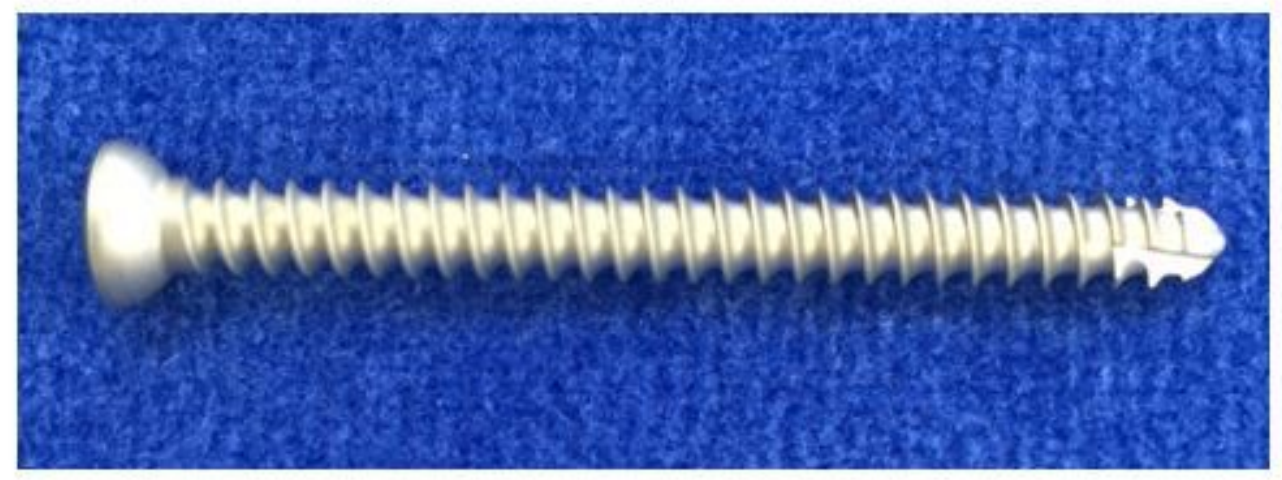

Figure 7

one sample of $3.5 \mathrm{~mm}$ self-tapping screw

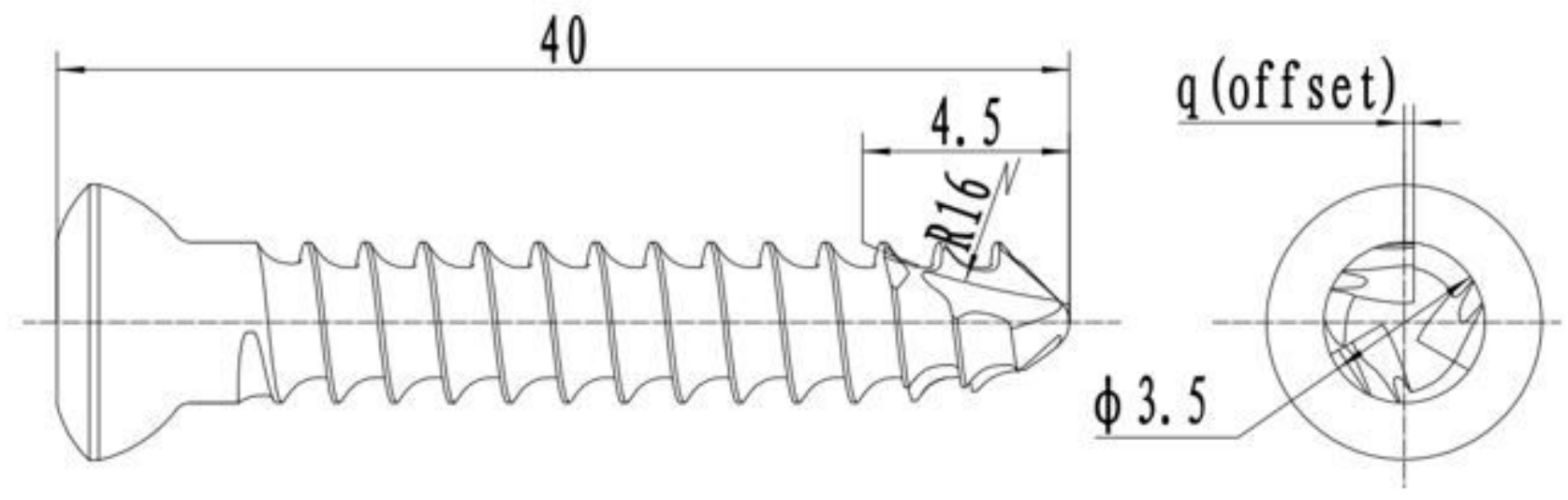

Figure 8

Cutting flute offset design 


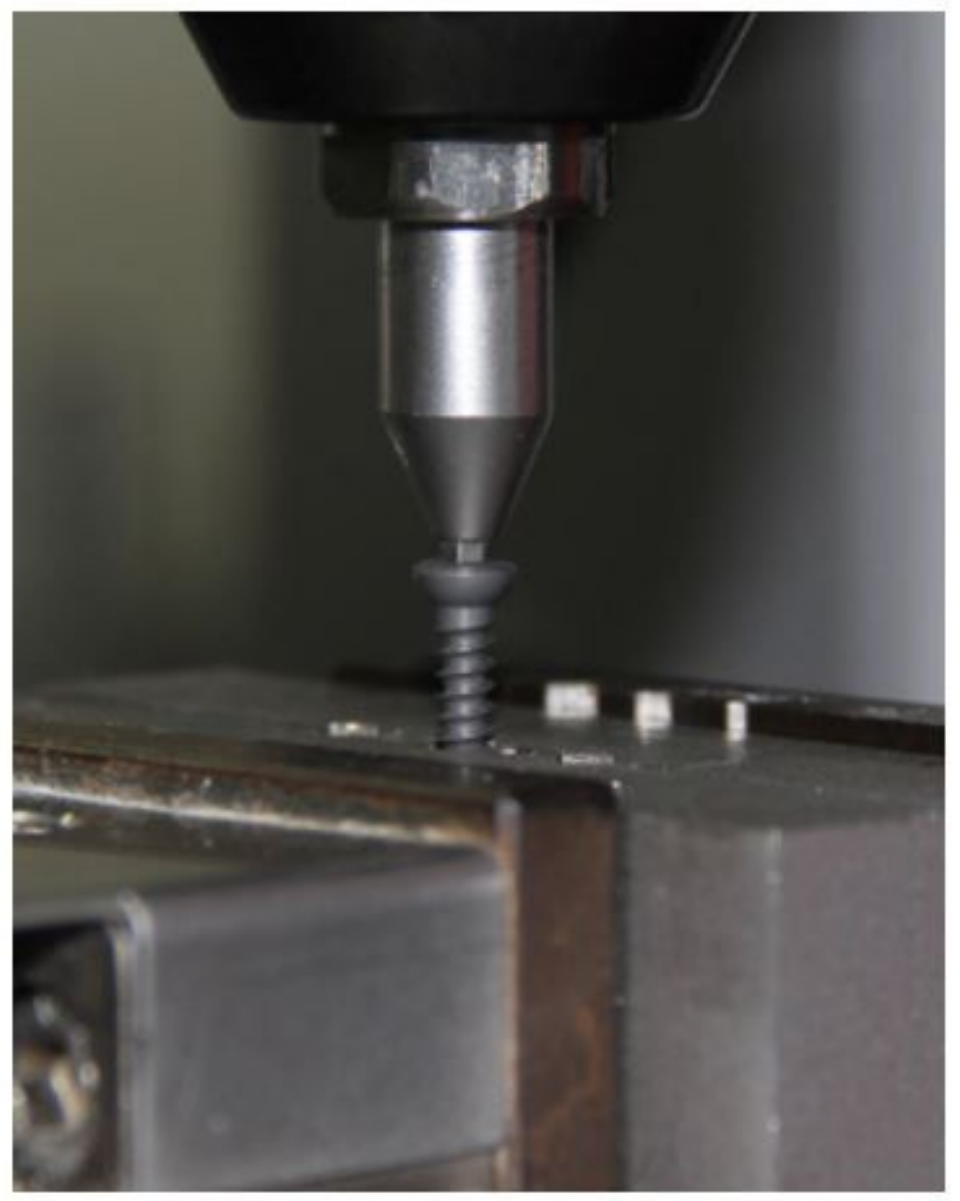

Figure 9

Torsional test set up 


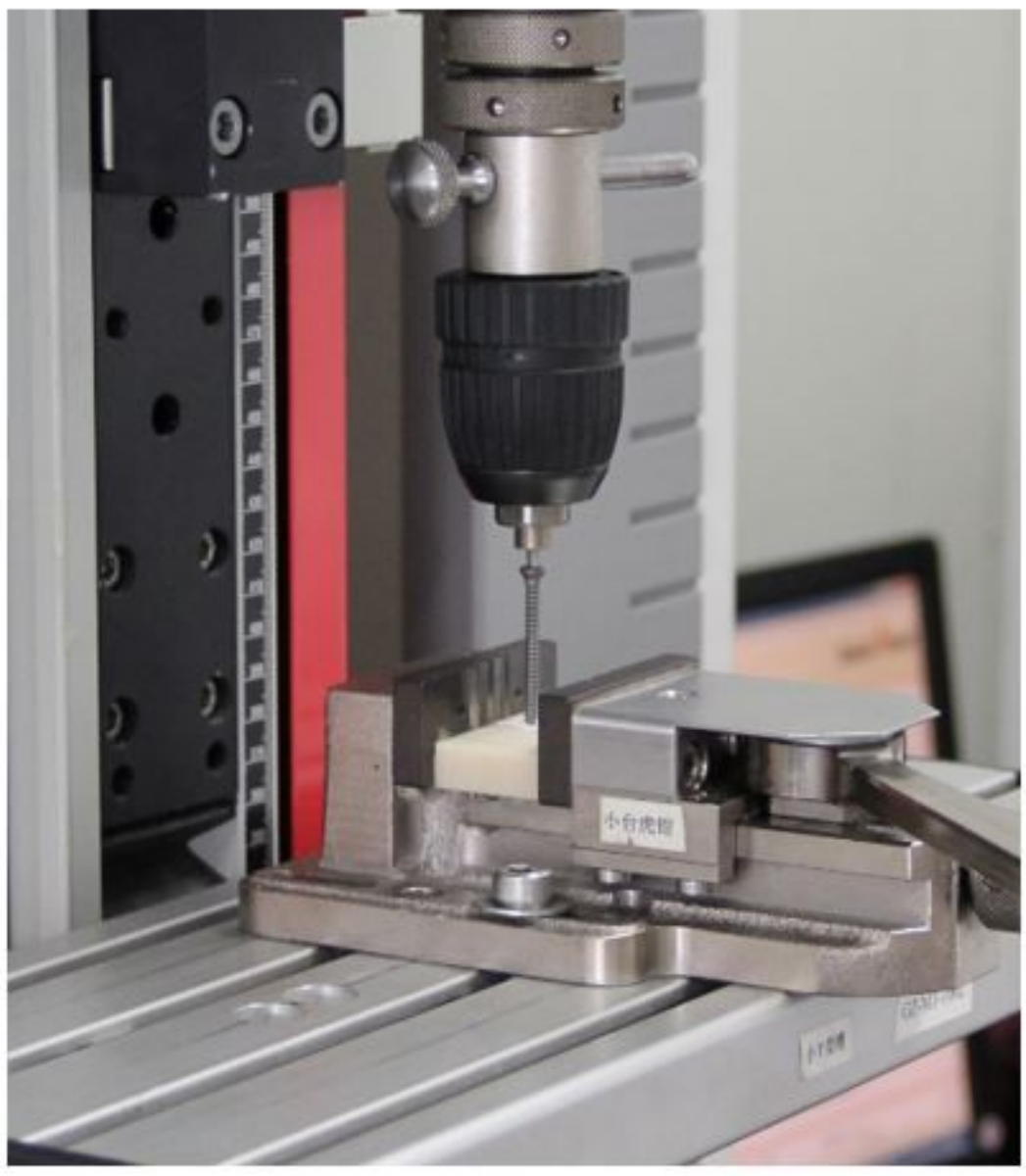

Figure 10

Insertion test set up 

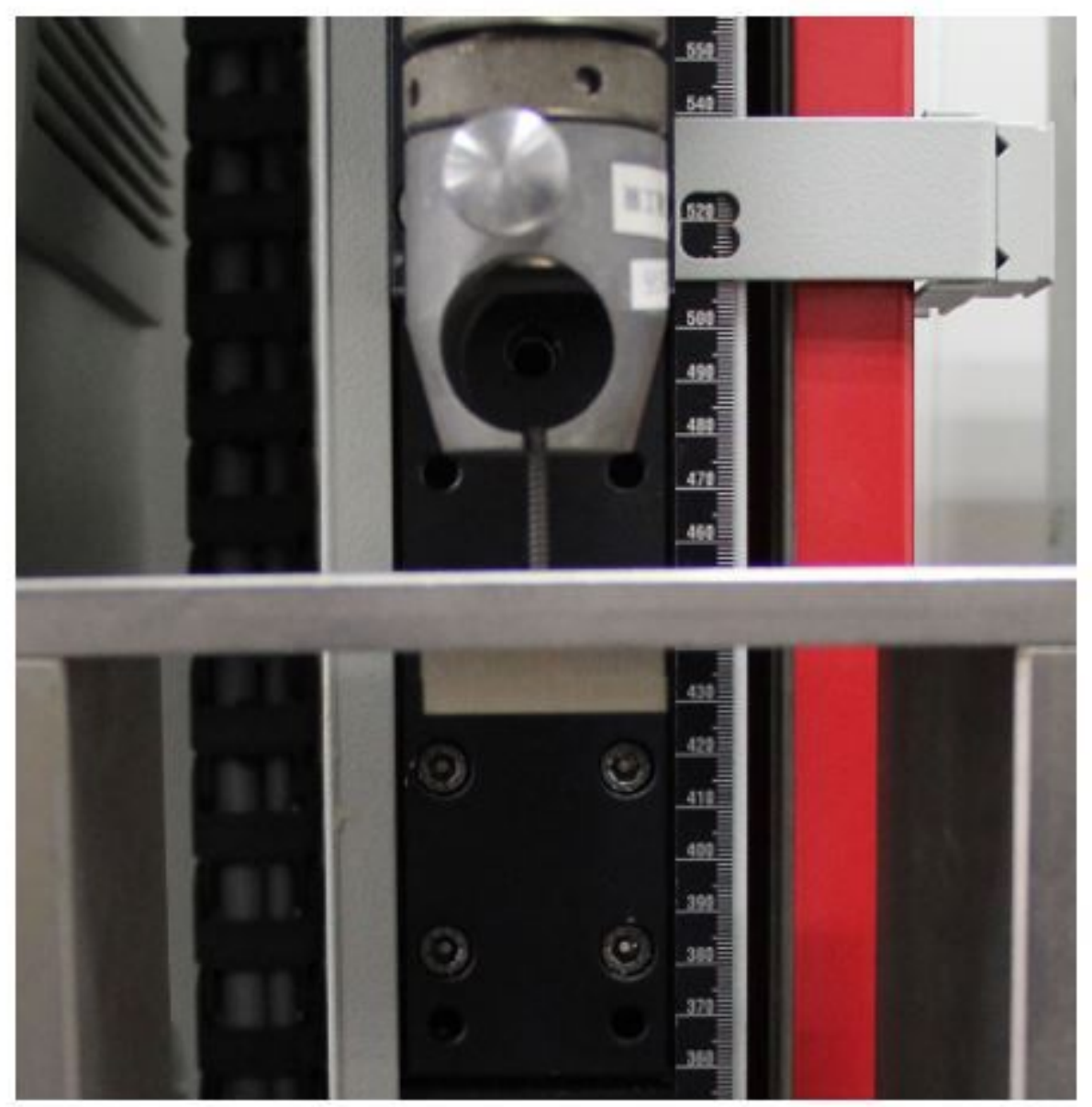

Figure 11

Pullout test set up 